\section{The Polysymptomatic Distress Scale Is Simple, Useful, and Effective in Clinical Care and Clinical and Epidemiology Studies}

To the Editor:

The Friend and Bennett editorial ${ }^{1}$ in a recent issue of The Journal continues a quarrel with the 2010 American College of Rheumatology (ACR) Preliminary Diagnostic Criteria for Fibromyalgia (FM) ${ }^{2}$ and the followup research criteria of $2011^{3}$ that was begun by Bennett shortly after first publication, and which has continued to date. It has taken the form of vigorous opposition to the acceptance and publication of our work during the manuscript review process, in disapprobation in editorials and interviews, and in articles opposed to our work. They label the many-authored 2010 ACR criteria and the 2011 modification as "Dr. Wolfe's diagnostic criteria for fibromyalgia" in this editorial and the "Wolfe criteria" elsewhere. We know of no other ACR criteria currently in use that is referred to by the author's name.

Friend and Bennett's objection to the Polysymptomatic Distress Scale (PSD) is based on 3 points. First, "The PSD relies on the 19-point WPI [Widespread Pain Index] component as its primary assessment of pain. However, the WPI is inherently unrepresentative of pain regions; in its development only non-articular regions were selected, and articular ones eliminated based on statistical criteria with the goal of FM classification..." We must reply that the WPI is a measure of pain extent, not a primary assessment of pain. The choice of non-articular regions was deliberate. It was made to correspond to non-articular pain and to be resistant to primary joint disease. However, as we have shown, using articular regions will work too, and almost as well ${ }^{4}$. The proper issue is whether a shortened scale works sufficiently well. Our data say that it does. We await Friend and Bennett's data saying that it does not.

The second objection is that the WPI relies on "the number of pain sites as a measure of pain severity, with the assumption that more pain sites equate with more pain intensity. By definition, therefore, disorders that have more pain sites will necessarily have more pain than disorders with fewer pain sites. On the other hand, for disorders with fewer pain sites, there is little room in the WPI pain count for a disorder with high pain intensity, such as gout or migraine." That is Friend and Bennett's interpretation, not ours, and is clearly wrong. We say in the 2010 and 2011 papers that the WPI measures pain extent, not severity. We do not want people to use the WPI to measure pain severity (Table 3, 2010 criteria) ${ }^{2}$, and please do not use the WPI or PSD to assess acute gout or migraine headache.

"A third problem is the under representation of pain qualities in the PSD." We fail to see this as a problem. The PSD is not and was not designed as a "pain qualities scale," nor should it have been.

They have a few other objections. The Symptom Severity Scale, although it evaluated a huge number of candidate variables, did not include variables that they say the "clinical and research literature $[\ldots]$ found to be pertinent to the assessment of severity, as for example, stiffness, balance, tenderness to touch, environmental sensitivity, and physical functioning. Physical functioning was omitted: 'because our scales were designed primarily for aiding in diagnosis"'. We suggest that Friend and Bennett might contemplate the specificity of items like stiffness, the generalizability of balance questions, and the difficulty of defining environmental sensitivity in a 4-item questionnaire, among other reasons for omissions.

Although Friend and Bennett have found problems with using the PSD to assess disease severity, we have not. More than 15,000 patients have completed the PSD. We invite readers to explore the comprehensive data in support of this scale that we have presented in The Journal ${ }^{5}$ and elsewhere ${ }^{6,7}$, and we suggest Friend and Bennett review the data of
Brummett, et al, who have used the PSD effectively ${ }^{8}$. Friend and Bennett, however, appear to have another suggestion. "We would suggest," they write, "that our own scale, the SIQR [Symptom Impact Questionnaire], a disease-neutral version of the FIQR [Fibromyalgia Impact Questionnaire], could be considered as an alternative. 9 " We await data on the general acceptance of their scale and its use in population and other broad-based studies.

FREDERICK WOLFE, MD, National Data Bank for Rheumatic Diseases, Wichita, and University of Kansas School of Medicine, Wichita, Kansas, USA; BRIAN T. WALITT, MD, Rheumatology, Washington Hospital Center, Washington, DC, USA; JOHANNES J. RASKER, MD, Faculty Behavioral Sciences, Department of Psychology, Health and Technology, University of Twente, Enschede, the Netherlands; ROBERT S. KATZ, MD, Rheumatology, Rush University Medical Center, Chicago, Illinois, USA; WINFRIED HÄUSER, MD, Department of Psychosomatic Medicine and Psychotherapy, Technische Universität München, Munich, Germany. Address correspondence to Dr. F. Wolfe, National Data Bank for Rheumatic Diseases, 1035 N. Emporia, Ste. 230, Wichita, Kansas 67214, USA.E-mail: fwolfe@ arthritis-research.org

\section{REFERENCES}

1. Friend R, Bennett RM. A critical examination of the Polysymptomatic Distress Scale construct as a symptom severity questionnaire. J Rheumatol 2015;42:1364-7.

2. Wolfe F, Clauw DJ, Fitzcharles MA, Goldenberg DL, Katz RS, Mease $\mathrm{P}$, et al. The American College of Rheumatology preliminary diagnostic criteria for fibromyalgia and measurement of symptom severity. Arthritis Care Res 2010;62:600-10.

3. Wolfe F, Clauw DJ, Fitzcharles MA, Goldenberg DL, Häuser W, Katz RS, et al. Fibromyalgia criteria and severity scales for clinical and epidemiological studies: a modification of the ACR Preliminary Diagnostic Criteria for Fibromyalgia. J Rheumatol 2011; 38:1113-22.

4. Walitt B, Nahin RL, Katz RS, Bergman MJ, Wolfe F. The prevalence and characteristics of fibromyalgia in the 2012 National Health Interview Survey. PLoS One 2015;10:e0138024.

5. Wolfe F, Walitt BT, Rasker JJ, Katz RS, Häuser W. The use of polysymptomatic distress categories in the evaluation of fibromyalgia (FM) and FM severity. J Rheumatol 2015;42:1494-501.

6. Wolfe F, Brähler E, Hinz A, Häuser W. Fibromyalgia prevalence, somatic symptom reporting, and the dimensionality of polysymptomatic distress: results from a survey of the general population. Arthritis Care Res 2013;65:777-85.

7. Häuser W, Brähler E, Wolfe F, Henningsen P. Patient Health Questionnaire 15 as a generic measure of severity in fibromyalgia syndrome: surveys with patients of three different settings. J Psychosom Res 2014;76:307-11.

8. Brummett CM, Janda AM, Schueller CM, Tsodikov A, Morris M, Williams DA, et al. Survey criteria for fibromyalgia independently predict increased postoperative opioid consumption after lower-extremity joint arthroplasty: a prospective, observational cohort study. Anesthesiology 2013;119:1434-43.

9. Friend R, Bennett RM. Distinguishing fibromyalgia from rheumatoid arthritis and systemic lupus in clinical questionnaires: an analysis of the revised Fibromyalgia Impact Questionnaire (FIQR) and its variant, the Symptom Impact Questionnaire (SIQR), along with pain locations. Arthritis Res Ther 2011;13:R58.

J Rheumatol 2016;43:2; doi:10.3899/jrheum.150926 